\title{
Clinical outcomes of Ti-Ni shape-memory patella concentrator combined with cannulated compression screws in the treatment of C2 and C3 patella fracture: a retrospective study of 54 cases
}

\author{
Chen $\mathrm{Yao}^{\dagger}$, Jie Sun ${ }^{\dagger}$, Jiancheng Wu, Zhenyu Zhou, Fan Liu, Ran Tao and Yafeng Zhang ${ }^{*}$ (i)
}

\begin{abstract}
Background: Ti-Ni shape-memory patella concentrator (TNSMPC) has been designed as an alternative approach for fixation of patella fracture, which has some advantages like higher hardness, higher tenacity, better wearing resistance, excellent corrosion resistance and desired histocompatibility. The present study was to investigate the efficiency of TNSMPC combined with cannulated compression screws in the treatment of comminuted patella fractures.

Methods: Between January 2014 and December 2017, 54 patients of C2 and C3 patella fractures underwent open reduction and internal fixation with TNSMPC combined with cannulated compression screws. All the patients got standard postoperative rehabilitation programs and were regularly followed up for at least 12 months after the operation. X-rays, knee functions and life quality were evaluated during the follow-up.

Results: All the patients achieved bone healing and recovery of knee function with low incidence of complications according to outcomes of $\mathrm{X}$-rays and questionnaires. The average operation time and blood loss during surgery were $77.5 \pm 25.12 \mathrm{~min}$ and $24.25 \pm 4.70 \mathrm{ml}$ respectively. The Knee Outcome Survey Activities of Daily Living Scale, the range of motion and the 36-item short-form heath survey after the operation were all improved. According to the Bostman's criteria, the excellent to good rate was $92.6 \%$.

Conclusion: TNSMPC combined with cannulated compression screws is an effective internal fixation method for C2 and C3 patella fracture with excellent clinical outcomes. In addition, the operation does not increase extra technique difficulty or tissue damage relatively, which is worth promotion.
\end{abstract}

Keywords: Shape-memory patella concentrator, Comminuted patella fracture, Fixation technique, Clinical outcomes

* Correspondence: fcius2004@hotmail.com

${ }^{\dagger}$ Chen Yao and Jie Sun contributed equally to this work.

Department of Orthopaedics, The Affiliated Hospital of Nantong University,

Nantong City, Jiangsu Province, PR China

C C The Author(s). 2020 Open Access This article is licensed under a Creative Commons Attribution 4.0 International License, which permits use, sharing, adaptation, distribution and reproduction in any medium or format, as long as you give appropriate credit to the original author(s) and the source, provide a link to the Creative Commons licence, and indicate if changes were made. The images or other third party material in this article are included in the article's Creative Commons licence, unless indicated otherwise in a credit line to the material. If material is not included in the article's Creative Commons licence and your intended use is not permitted by statutory regulation or exceeds the permitted use, you will need to obtain permission directly from the copyright holder. To view a copy of this licence, visit http://creativecommons.org/licenses/by/4.0/ The Creative Commons Public Domain Dedication waiver (http://creativecommons.org/publicdomain/zero/1.0/) applies to the data made available in this article, unless otherwise stated in a credit line to the data. 


\section{Background}

The patella is the biggest sesamoid bone inside the human body, located between the quadriceps tendon and the patella tendon. As an important module in the knee extension system, the patella can function as a lever and increase the moment of quadriceps, enabling the extension of the knee and helping maintain the stability of knee joint [1]. The incidence of patella fracture in young people (18-49 years) is $0.01 \%$ [2]. What's more, the incidence of patella fractures in adult including elder people is as high as $1.5 \%$, accounting for $10 \%$ of all fractures [3]. Comminuted patella fractures (AO/OTA $34 \mathrm{C} 2$ and 34C3) are common challenges for orthopedic surgeons. Anatomical reduction and stable fixation are standard management to restore disrupted extension system and articular surface. Regardless of what kind of treatment was applied, there are still some patients who suffered poor outcomes from those comminuted patella fractures $[4,5]$.

While the operative techniques of patella fractures have undergone many changes over the past few decades, anterior tension band remains the most widely accepted method [6-8]. It can transfer tension into pressure force to achieve dynamic compression between fragments, allowing early joint motion. However, the tension band still has many disadvantages $[9,10]$. The traditional tension band is composed of smooth Kirschner wires (K-wire) and stainless wires. The smooth Kwires cannot provide direct fragmentary compression and the fracture may separate when the knee extends [11]. In addition, when the tension band is working, the stainless wires and K-wires may have stress break, wearing, loosening, migration and skin irritation. Some orthopedic surgeons have presented different modified tension band methods to avoid the shortcomings of traditional tension band, such as cannulated screws combined with stainless wires or cannulated screws combined with titanium cables. However, the early failures of tension band were still reported in the literatures with the rate of 12 to $30 \%$, especially in comminuted fractures $[12,13]$.

Titanium-nickel (Ti-Ni) alloy is an one-way shapememory alloy, which can be contoured in low temperature and reconverted to the previous shape in high temperature. Compared with traditional K-wires, the $\mathrm{Ti}-\mathrm{Ni}$ shape-memory alloy has higher hardness, higher tenacity and better wearing resistance. What's more, it has excellent corrosion resistance and desired histocompatibility [14, 15]. Based on these advantages, some Chinese factories have designed and manufactured patella concentrator out of $\mathrm{Ti}-\mathrm{Ni}$ shape-memory alloy as an alternative approach for fixation of patella fractures. (Fig. 1).

During the past several years, we applied the specialdesigned $\mathrm{Ti}-\mathrm{Ni}$ shape-memory patella concentrator (TNSMPC) combined with cannulated screws in the treatment of $\mathrm{C} 2$ and $\mathrm{C} 3$ patella fractures and conducted complete follow-up. In this paper, we presented our operation techniques. Additionally, we retrospectively collected and analyzed the existing clinical data of follow-up, evaluating clinical outcomes of this method.

\section{Materials and methods}

\section{Patients}

The retrospective study was conducted in Trauma Unit of the Department of Orthopaedics, the Affiliated Hospital of Nantong University, and approved by the Clinical Research Ethics Committee of the Institution. All works complied with the principles in the declarations of Helsinki. Between January 2014 and December 2017, all patients who came to our institution with patella fractures was evaluated for this study according to the special protocol shown in Fig. 2. The written informed consent was obtained from all patients. Inclusion criteria
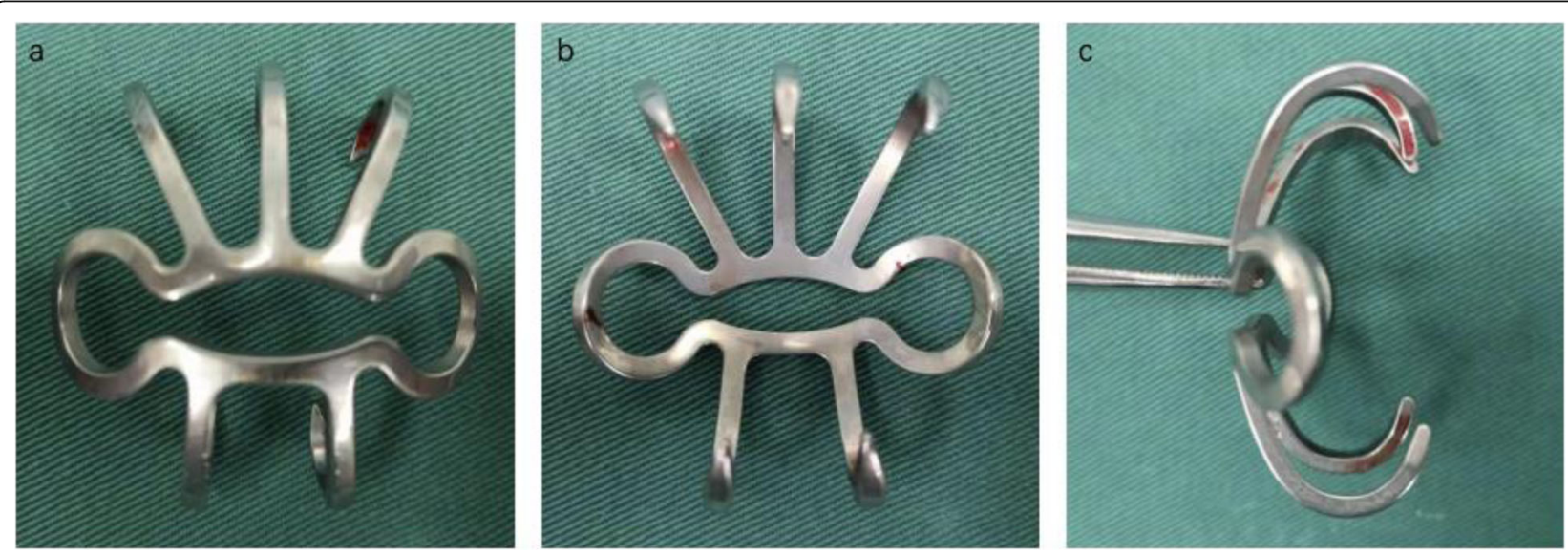

Fig. 1 Diagram of the special-designed Ti-Ni shape-memory patella concentrator (SEEMINE, Lanzhou China, TN) for the fixation of patella fractures 


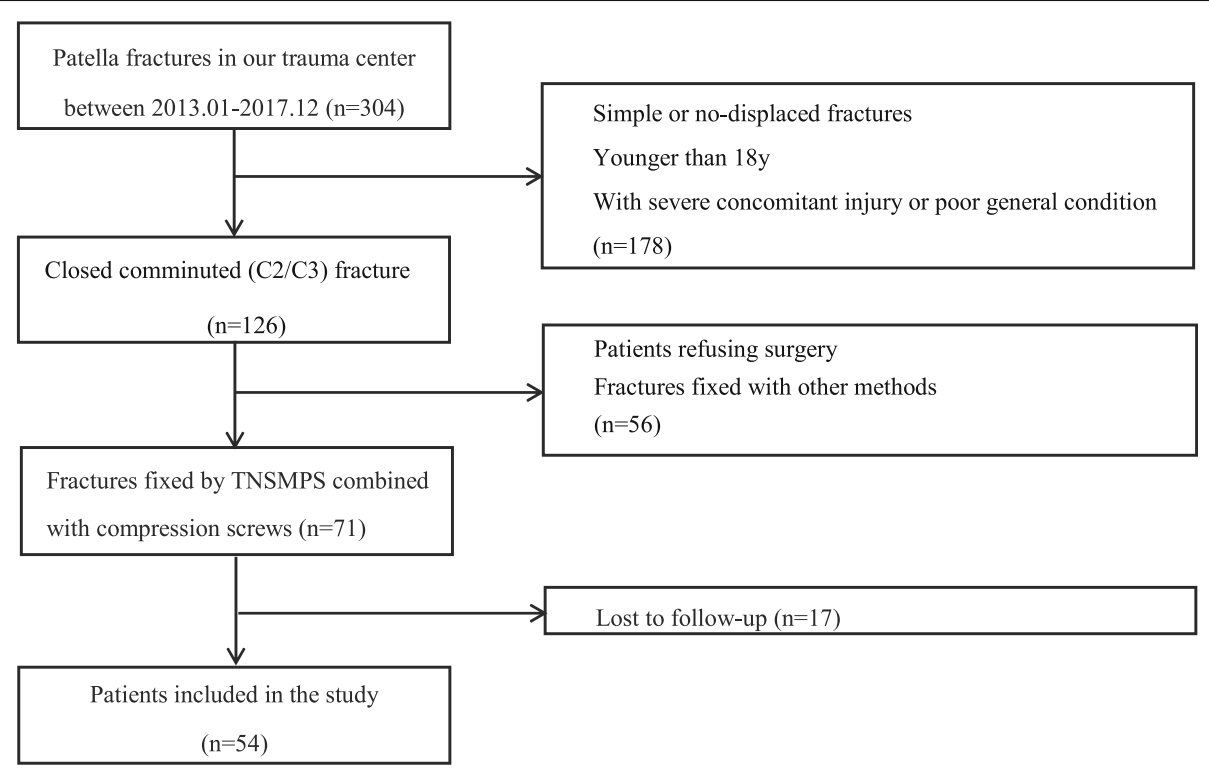

Fig. 2 Flowchart of participants through the study

were: comminuted patella fracture (AO/OTA $34 \mathrm{C} 2$ and 34C3), indication for surgery (broken of knee extensor mechanism, fracture displacement of more than $3 \mathrm{~mm}$, cartilage step-off of more than $2 \mathrm{~mm}$ ), application of Ti$\mathrm{Ni}$ shape-memory patella concentrator (TNSMPC) combined with cannulated screws, aged 18 years and above at the time of injury. Exclusion criteria were: simple or nondisplaced fracture with indication for conservative treatment (fracture displacement of no more than $3 \mathrm{~mm}$ or cartilage step-off of less than $2 \mathrm{~mm}$ ), aged younger than 18 years, function limitation of the knee or other severe medical conditions before injury, multiple concomitant injuries of the ipsilateral leg or other systems, lost of follow-up.

\section{Perioperative management}

After hospitalization, the injuried knee was temporarily fixed with splints in extension to release the pain. Standard anterior-posterior and lateral view $\mathrm{X}$-rays were proceeded. Computerized tomography scan and threedimensional reconstruction were performed for severely comminuted and displaced patella fractures. All fractures were classified according to AO/OTA classification system. Pre-operative function evaluation was gathered from medical documents. Open reduction and internal fixation were performed in 5 days since injury. Quadriceps contraction exercises and continuous passive motion (CPM) were carried out the day after operation. Partial weight bearing and active range-of-motion (ROM) exercises with a mobilizable brace were encouraged 1 week after operation. Full weight bearing walk was allowed 6 weeks after operation.

\section{Operation techniques}

All patients got the operation under general anesthesia and supine position. The tourniquet was applied during the operation with $300 \mathrm{mmHg}$ pressure. Anterior longitudinal incision was carried out to expose the fracture. The fractures were reduced and temporarily fixed with reposition forceps and guide pins of cannulated screws, and the reduction quality was checked by $\mathrm{C}$-arm fluoroscopy simultaneously. If the reduction of the fracture was acceptable, cannulated screws with appropriate length were screwed in to fix the fracture fragments and provide direct fragmentary compression. The pre-patella bursa was sutured. TNSMPC was contoured in $0{ }^{\circ} \mathrm{C}$ sterilized normal saline and clasped the patella. The superior and inferior claws was respectively embedded into the tendon around the upper and lower patella pole, like a talon catching a prey. The concentrator was reconverted to the previous shape in $37{ }^{\circ} \mathrm{C}$ sterilized normal saline after implantation, which provided mechanical effects as a tension band. Stability of fracture fixation was confirmed with the knee in flexion of at least 90 degrees. Position of internal fixation and ROM of the joint were checked as well before closing the incision.

\section{Follow-up assessment}

Follow-up assessment was performed at 3, 6, and 12 months after the operation, including X-rays and knee function. Patients' life quality was evaluated at 12 months after the operation. The Knee Outcome Survey Activities of Daily Living Scale (KOS-ADL), ROM measurement, Bostman score and 36-item Short-form heath survey (SF-36) were applied in the process. The standards for clinical and bone healing of fracture healing 
were as the following: there was no local tenderness, no local tapping pain and patients can raised the injuried leg with the knee in extension easily; X-rays showed the fracture line is blurred and continuous callus passed through the fracture line.

\section{Statistical analysis}

Statistical analysis was performed with the Graphpad Prism 7. Mogorov-Smirnov test was used to evaluate normal distribution. The normal distribution is expressed by mean ( \pm standard deviation), while the non-normal distribution is expressed by median (25th and 75th percentiles) or number (percentage). The student $t$ test and chi-square test were applied to compare the continuous variables and categorical variables respectively between different groups. $P$ value of less than 0.05 was considered statistically significant.

\section{Results}

Finally, 54 patients who accepted open reduction and internal fixation with TNSMPC combined with cannulated screws for comminuted patella fracture were evaluated in this study. All the cases were close fractures, without other concomitant injuries. Baseline demographic and clinical characteristics of the patients were summarized in Table 1. There were 31 males and 23 females. The

Table 1 Baseline demographic and clinical characteristic of patients

\begin{tabular}{ll}
\hline Characteristic & Description \\
\hline Age, years (mean \pm SD) & $54.11 \pm 11.24$ \\
Gender, n\% & \\
Male & $31(57.4)$ \\
Female & $23(42.6)$ \\
Side of injury & \\
Left & $33(61.1)$ \\
Right & $21(38.9)$ \\
BMl, kg/m ${ }^{2}$ (mean \pm SD) & $23.02 \pm 4.30$ \\
Mechanism of injury, n\% & \\
Daily activity & \\
Work & $9(16.7)$ \\
Traffic accident & $28(51.9)$ \\
Sports injury & $10(18.5)$ \\
Activities in daily life & $7(13.0)$ \\
OTA classification & \\
C2 & $23(42.6)$ \\
C3 & $31(57.4)$ \\
Hospital stay, day (mean \pm SD) & $14.67 \pm 4.40$ \\
Operation time, min (mean \pm SD) & $77.50 \pm 25.12$ \\
Blood loss, ml (mean $\pm S D)$ & $24.25 \pm 4.70$ \\
\hline
\end{tabular}

average age of patients were $54.11 \pm 11.24$ years (range: $28-83$ years). The average body mass index (BMI) was $23.02 \pm 4.30 \mathrm{~kg} / \mathrm{m}^{2}$. Thirty-three fractures happened in the left side and 21 fractures happened in the right side. The injury mechanisms included traffic accidents (28 patients), sports (10 patients), works (9 patients) and activities in daily life (7 patients). According to the $\mathrm{AO} /$ OTA classification system, there were $23 \mathrm{C} 2$ fractures and $31 \mathrm{C} 3$ fractures. The average hospitalization was $14.67 \pm 4.40$ days. The average operation time was $77.5 \pm$ $25.12 \mathrm{~min}$ and the average blood loss during the operation was $24.25 \pm 4.70 \mathrm{ml}$ (range: $20-40 \mathrm{ml}$ ).

All the patients got clinical healing 3 months after operation and bone healing 6 months after operation according to the results of radiographic and clinical evaluation. No broken, loosening, migration and skin irritation of the internal fixation were detected, which means excellent performance and histocompatibility of TNSMPC. The ROM for extension-flexion of the injuried knee improved significantly $(P<0.0001)$ from $108.91^{\circ} \pm 4.95^{\circ} 3$ months after operation to $124.28^{\circ} \pm$ $5.09^{\circ} 6$ months after operation and $136.11^{\circ} \pm 4.42^{\circ} 12$ months after operation, and closed to the uninjuried contralateral knee $\left(146.42^{\circ} \pm 3.43^{\circ}\right)$ (Fig. 3). The KOSADL was evaluated at least 6 months after the operation. The results showed only a few patients had symptoms severely influencing their daily activities (Table 2). Kneeling and squatting were limited for several patients and other functions were not difficult for patients (Table 3). SF-36 survey 1 years after the operation indicated the quality life of the patients were almost restored (Table 4). The results of role physical evaluation were relatively lower than other items, which indicated

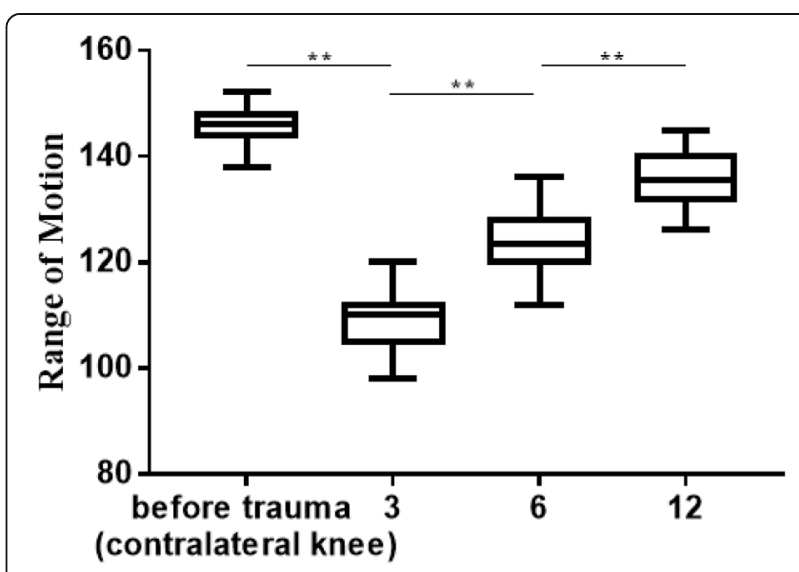

\section{Time after surgery(months)}

Fig. 3 Histogram of the ROM for extension-flexion at follow up. The ROM for extension-flexion of the injured knee improved significantly from $108.91^{\circ} \pm 4.95^{\circ}$ after 3 months to $124.28^{\circ} \pm 5.09^{\circ}$ after 6 months and $136.11^{\circ} \pm 4.42^{\circ}$ after 12 months, close to the uninjured contralateral knee $\left(146.42^{\circ} \pm 3.43^{\circ}\right)^{* *}$ : t-test, $P<0.0001$ 
Table 2 KOS-ADL evaluation (Symptoms) 1 year after the surgery

\begin{tabular}{|c|c|c|c|c|c|c|c|}
\hline & $\begin{array}{l}\text { I do not have the } \\
\text { symptom in my } \\
\text { knee }\end{array}$ & $\begin{array}{l}\text { I have the symptom, } \\
\text { but it does not affect } \\
\text { my activity }\end{array}$ & $\begin{array}{l}\text { The symptom } \\
\text { affects my activity } \\
\text { slightly }\end{array}$ & $\begin{array}{l}\text { The symptom } \\
\text { affects my activity } \\
\text { moderately }\end{array}$ & $\begin{array}{l}\text { The symptom } \\
\text { affects my activity } \\
\text { severely }\end{array}$ & $\begin{array}{l}\text { The symptom } \\
\text { prevents me from all } \\
\text { daily activity }\end{array}$ & $\begin{array}{l}\text { NO } \\
\text { answer }\end{array}$ \\
\hline Pain & 22 & 9 & 14 & 4 & 5 & 0 & 0 \\
\hline Stiffness & 30 & 4 & 8 & 3 & 5 & 0 & 4 \\
\hline Swelling & 28 & 8 & 6 & 4 & 4 & 0 & 4 \\
\hline Slipping & 20 & 9 & 8 & 4 & 9 & 0 & 4 \\
\hline Buckling & 19 & 9 & 11 & 5 & 8 & 0 & 2 \\
\hline Weakness & 29 & 6 & 6 & 6 & 2 & 2 & 3 \\
\hline
\end{tabular}

patients may need appropriate physical rehabilitation training respectively after the operation. According to the Bostman score, among all the 54 patients, 38 patients were excellent, 12 cases were good. The Fig. 4 showed a demo case.

\section{Discussion}

The purpose of this retrospective case series was to evaluate the clinical outcomes of TNSMPC combined with cannulated compression screws in the treatment of comminuted patella fractures. The results revealed good clinical outcomes and few complications of this technique, which achieved high level of patient's satisfaction. Due to the reliable fixation provided by the implants, patients were allowed to full weight bearing and rehabilitation after the surgery as soon as possible. All patients got bone healing 6 months after operation, with improved knee function, better life quality and few severe complications. In addition, the average operation time was $77.5 \mathrm{~min}$ and average blood loss was $25.5 \mathrm{ml}$, which means this operation method may not increase extra technique difficulties or tissue damages and it worth being promoted widely.

KOS-ADL and ROM are the most commonly used to evaluate the function of the knee after the surgery like arthroscopy, arthroplasty or fracture. The Bostman score reflects the patients' subjective satisfaction to the treatments. Particularly, as a concise health questionnaire, SF-36 comprehensively summarizes the quality of life of the respondent from eight aspects: physiological function, physiological function, physical pain, general health, vitality, social function, role emotional and mental health. The vast majority of patients recovered significantly in terms of body function and quality of life after surgery in our study, while there are a small number of subjects who cannot kneel, squat or go down stairs easily after the surgery. We think it is a failure of patients to perform proper functional exercise after surgery and related to the fact that some patients themselves are too old and have poor mobility. Generally, the ROM of injured knee, function scores and life quality evaluation of patients indicated excellent recovery 1 years after surgery compared with the perioperative period.

Longitudinal K-wires combined with stainless wire in a figure-8 pattern was a classical fixation method for patella fractures and has been widely applied for decades. The cannulated compression screws can be applied to replace the K-wire without threads to provide direct fragmentary compression with the knee in extension [16]. However, the early failure of the internal fixation

Table 3 KOS-ADL evaluation (Functional limitations) 1 year after the surgery

\begin{tabular}{|c|c|c|c|c|c|c|c|}
\hline & $\begin{array}{l}\text { Activity is not } \\
\text { difficult }\end{array}$ & $\begin{array}{l}\text { Activity is minimally } \\
\text { difficult }\end{array}$ & $\begin{array}{l}\text { Activity is somewhat } \\
\text { difficult }\end{array}$ & $\begin{array}{l}\text { Activity is fairly } \\
\text { difficult }\end{array}$ & $\begin{array}{l}\text { Activity is very } \\
\text { difficult }\end{array}$ & $\begin{array}{l}\text { I am unable to do the } \\
\text { activity }\end{array}$ & $\begin{array}{l}\text { No } \\
\text { answer }\end{array}$ \\
\hline Walk & 25 & 13 & 8 & 3 & 3 & 0 & 2 \\
\hline Go up stairs & 17 & 18 & 5 & 9 & 3 & 0 & 2 \\
\hline $\begin{array}{l}\text { Go down } \\
\text { stairs }\end{array}$ & 12 & 18 & 8 & 11 & 3 & 0 & 2 \\
\hline Stand & 27 & 12 & 5 & 2 & 5 & 0 & 3 \\
\hline $\begin{array}{l}\text { Kneel on } \\
\text { front }\end{array}$ & 4 & 12 & 9 & 6 & 9 & 12 & 2 \\
\hline Squat & 14 & 12 & 2 & 12 & 2 & 6 & 6 \\
\hline $\begin{array}{l}\text { Sit with knee } \\
\text { bent }\end{array}$ & 22 & 11 & 12 & 5 & 0 & 0 & 4 \\
\hline $\begin{array}{l}\text { Rise from a } \\
\text { chair }\end{array}$ & 20 & 12 & 6 & 8 & 3 & 0 & 5 \\
\hline
\end{tabular}


Table 4 SF-36 health survey 1 year after the surgery

\begin{tabular}{ll}
\hline & All patients $(n=54)$ \\
\hline Items & \\
$\mathrm{PCS}^{\mathrm{a}}$ & $63.84 \pm 18.45$ \\
$\mathrm{MCS}^{\mathrm{a}}$ & $74.81 \pm 14.29$ \\
$\mathrm{PF}^{\mathrm{b}}$ & $80(65,80)$ \\
$\mathrm{RP}^{\mathrm{b}}$ & $25(0,100)$ \\
$\mathrm{BP}^{\mathrm{b}}$ & $100(74,100)$ \\
$\mathrm{GH}^{\mathrm{a}}$ & $65.19 \pm 17.05$ \\
$\mathrm{VT}^{\mathrm{a}}$ & $68.06 \pm 15.91$ \\
$\mathrm{SF}^{\mathrm{a}}$ & $76.39 \pm 18.76$ \\
$\mathrm{RE}^{\mathrm{b}}$ & $100(58.33,100)$ \\
$\mathrm{MH}^{\mathrm{a}}$ & $77.63 \pm 6.97$ \\
\hline
\end{tabular}

Abbreviations: $P C S$ physical component summary, MCS mental component summary, PF physical function, $R P$ role-physical, $B P$ bodily pain, $G H$ general health, $V T$ vitality, $S F$ social function, $R E$ role emotional, $M H$ metal health ${ }^{a}$ : Values are presented as the mean $\pm S D,{ }^{b}$ : Values are presented as the median (IQR)

due to stress break, wearing, loosening, migration, electrolytic and skin irritation still exists, particularly for comminuted patellar fractures [12, 13]. To avoid intrinsic shortcomings of tension wiring, some new internal fixations have been designed and applied in clinical trials such as a fixed angle plate, a locking patella plate and TNSMPC in our study [17-19]. The TNSMPC applied in our study was designed according to the anatomical characteristics of patella and was made of $\mathrm{Ti}-\mathrm{Ni}$ alloy with high excellent corrosion resistance and desired histocompatibility. The TNSMPC can provide similar or even stronger dynamic compression between fragments like anterior tension band and can avoid the intrinsic defects of anterior tension band. The shape of the concentrator fits for the patella very well and the material is friendly to the soft tissue, reducing risk of skin problems. In addition, $\mathrm{Ti}-\mathrm{Ni}$ alloy has excellent corrosion resistance and mechanical properties, which can provide stable fixation for comminuted fractures and avoid early stress break, wearing, loosening or migration. In terms of operation techniques, the install of the concentrator is much easier than that of stainless wire and the learning curve is short. After contoured in $0{ }^{\circ} \mathrm{C}$ sterilized normal saline and installed on the patella, concentrator was reconverted in $37^{\circ} \mathrm{C}$ normal saline and clasped the patella like a talon strongly, without any extra damage of soft tissue. Other new fixations, such as fixed-angle plating and locking plate, need extra screws to fix the plate on the patella and have limitations in osteoporotic patients or severely comminuted fractures [20]. However,

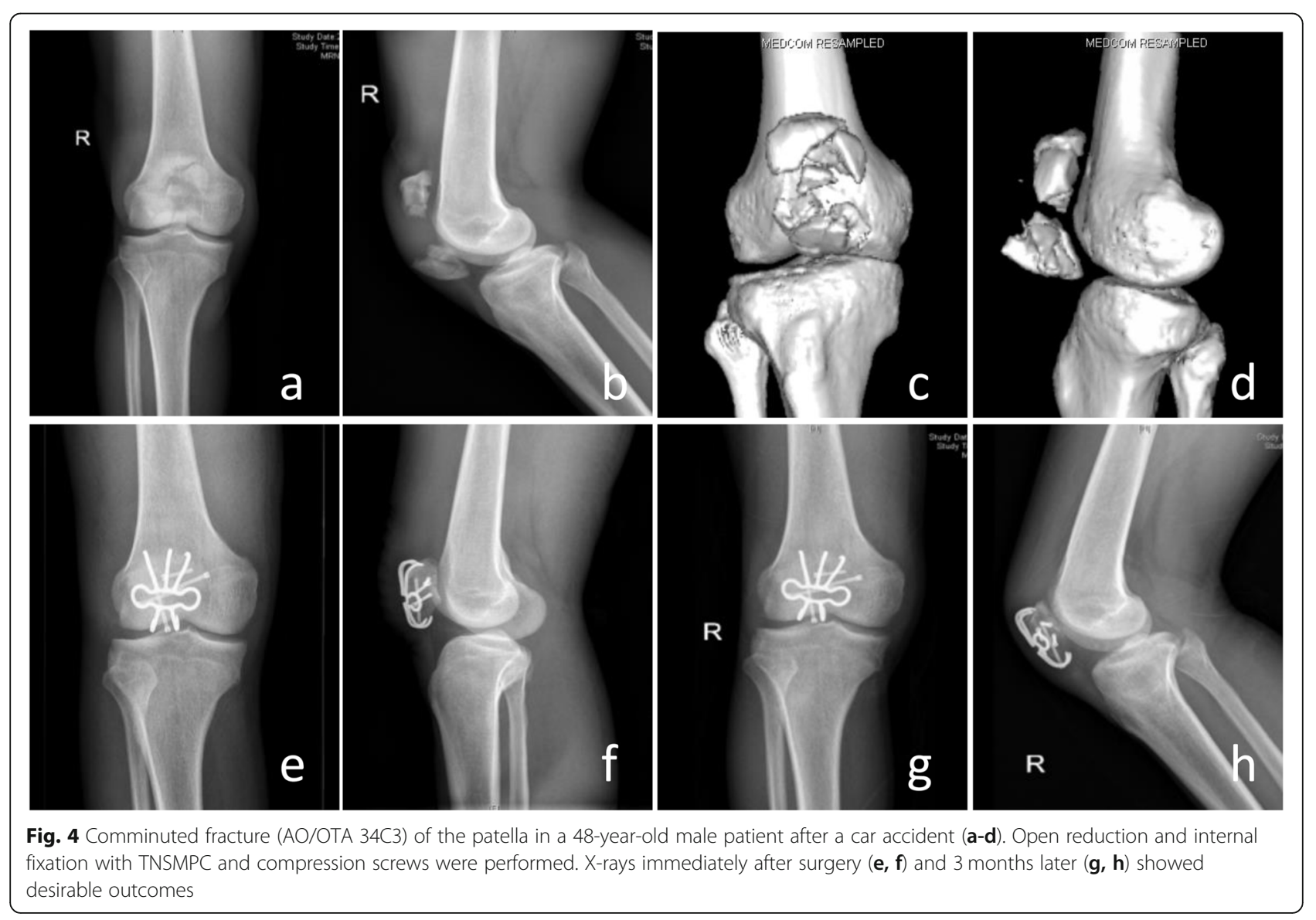




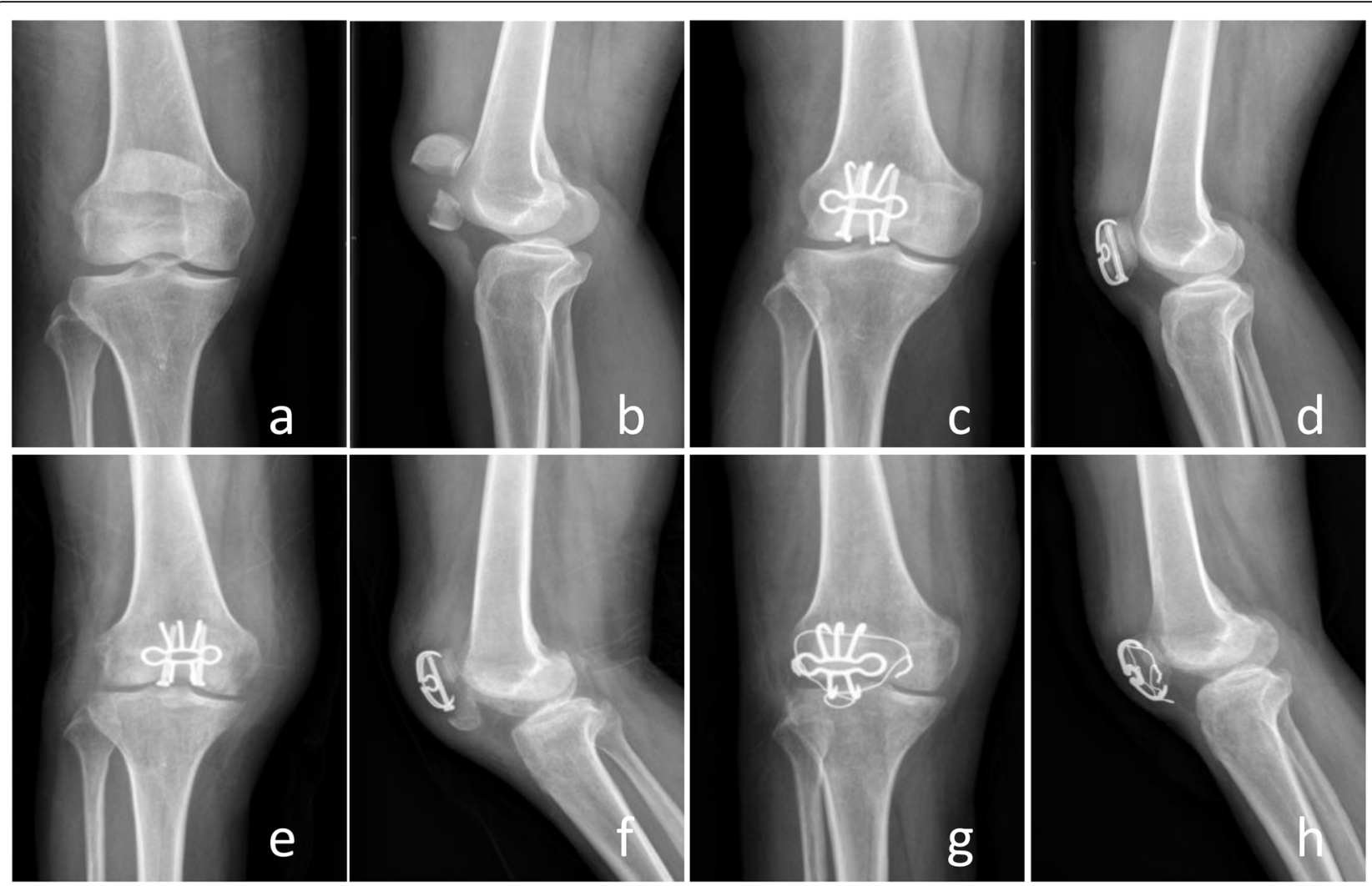

Fig. 5 Transverse fracture of the patella $(\mathbf{a}, \mathbf{b})$ in a 55-year-old female patient treated with TNSMPC and compression screws (c, d). The internal fixation failed 6 weeks after the surgery $(\mathbf{e}, \mathbf{f})$. The screws were removed and the claw and additional circle wire fixation were applied for revision surgery $(\mathbf{g}, \mathbf{h})$

the TNSMPC can fix the fracture independently by its claws and causes no extra bone loss, which can achieve excellent outcomes in osteoporotic or comminuted cases. The study conducted by Yutong Zhang et al., described another similar patella concentrator and reported desired outcomes in pole fracture or comminuted patella fractures [21]. Fracture displacement due to the loosening of the claw is a potential complication of the operation while it did not happen in cases with comminuted fractures. Figure 5 shows the failure of the internal fixation in a case with a simple transverse fracture and the revision surgery was performed by removing the screws, reducing the fracture and fixing it with the claw and additional circle wire. Factors related to the complications are not so clear, which may include choosing inappropriate size of the claw, malposition of the implants, poor bone quality, knee flexion too early after the operation and so on.

Several limitations of our study exist and deserve mention. Actually, this is a retrospective case series without a control group and we didn't compare the outcomes of our method with other osteosynthesis techniques directly, which affected the evidence level. We only chose comminuted fractures according to rigid standard in a single trauma center, so the number of cases are limited. Finally, the time of follow up was not so long. In the future, more cases from multiple trauma center and results of long-term follow up will be collected.

\section{Conclusion}

In summary, results of our study showed excellent outcomes of TNSMPC combined with cannulated compression screws in the treatment of $\mathrm{C} 2$ and $\mathrm{C} 3$ patella fracture. Without extra technique difficult or tissue damage, the TNSMPC and screws provide dynamic and static fragmentary compression respectively, ensuring stable fixation of comminuted patella fractures. Patients are allowed to early weight-bearing and rehabilitation without extra complications. As an alternative solution of traditional tension band, TNSMPC combined with cannulated compression screws is appropriate for comminuted patella fractures and worth spreading.

\section{Abbreviations}

BMI: Body mass index; CPM: Continuous passive motion; KOS-ADL: Knee Outcome Survey Activities of Daily Living Scale; K-wire: Kirschner wire; ROM: Range of motion; Ti-Ni: Titanium-nickel; TNSMPC: Ti-Ni shape-memory patella concentrator; PCS: Physical component summary; MCS: Mental component summary; PF: Physical function; RP: Role-physical; BP: Bodily pain; 
GH: General health; VT: Vitality; SF: Social function; RE: Role emotional; $\mathrm{MH}$ : Metal health; IQR: Interquartile range

\section{Acknowledgements}

None.

\section{Authors' contributions}

$C Y, R T$, and $Y Z$ conceived and designed the study. CY, JS and JW collected the data. CY, ZZ and FL performed the statistical analysis. CY wrote the manuscript. All authors approved the final version to be published.

\section{Funding}

This work was supported by the National Natural Science Foundation of China (No. 81501913), Natural Science Foundation of Jiangsu province (No. BK20151275) and Postgraduate Research \& Practice Innovation Program of Jiangsu Province (NO. SJCX19_0865).

\section{Availability of data and materials}

The datasets used and/or analysed during the current study are available from the corresponding author on reasonable request.

\section{Ethics approval and consent to participate}

This study was approved by the ethics committee of Affiliated Hospital of Nantong University and informed consent was obtained from all individual participants included in the study.

\section{Consent for publication}

All the participants have given their written informed consent for this study and agreed the date to be published.

\section{Competing interests}

The authors declare that they have no competing interests.

Received: 15 March 2020 Accepted: 23 July 2020

Published online: 31 July 2020

\section{References}

1. Koval KJ, Kim YH. Patella fractures. Evaluation and treatment. Am J Knee Surg. 1997;10(2):101-8

2. Farr JN, Melton $\sqcup J$ 3rd, Achenbach SJ, Atkinson EJ, Khosla S, Amin S. Fracture incidence and characteristics in young adults aged 18 to 49 years: a population-based study. J Bone Miner Res. 2017;32(12):2347-54. https:// doi.org/10.1002/jbmr.3228.

3. Carpenter JE, Kasman R, Matthews LS. Fractures of the patella. Instr Course Lect. 1994:43:97-108

4. LeBrun CT, Langford JR, Sagi HC. Functional outcomes after operatively treated patella fractures. J Orthop Trauma. 2012;26(7):422-6. https://doi.org/ 10.1097/BOT.0b013e318228c1a1.

5. Bonnaig NS, Casstevens C, Archdeacon MT, Connelly C, Monaco N, Wyrick $J \mathrm{D}$, Le TT. Fix it or discard it? A retrospective analysis of functional outcomes after surgically treated patella fractures comparing ORIF with partial patellectomy. J Orthop Trauma. 2015;29(2):80-4. https://doi.org/10.1097/ BOT.0000000000000201.

6. Kakazu R, Archdeacon MT. Surgical Management of Patellar Fractures. Orthop Clin North Am. 2016;47(1):77-83. https://doi.org/10.1016/j.ocl. 2015.08.010.

7. Melvin JS, Mehta S. Patellar fractures in adults. J Am Acad Orthop Surg. 2011:19(4):198-207. https://doi.org/10.5435/00124635-201104000-00004.

8. Curtis MJ. Internal fixation for fractures of the patella. A comparison of two methods. J Bone Joint Surg Br. 1990;72(2):280-2.

9. Choi HR, Min KD, Choi SW, Lee BI. Migration to the popliteal fossa of broken wires from a fixed patellar fracture. Knee. 2008;15(6):491-3. https://doi.org/ 10.1016/j.knee.2008.06.005

10. Carpenter JE, Kasman RA, Patel N, Lee ML, Goldstein SA. Biomechanical evaluation of current patella fracture fixation techniques. J Orthop Trauma. 1997;11(5):351-6. https://doi.org/10.1097/00005131-199707000-00009.

11. Zderic I, Stoffel K, Sommer C, Hontzsch D, Gueorquiev B. Biomechanical evaluation of the tension band wiring principle. A comparison between two different techniques for transverse patella fracture fixation. Injury. 2017;48(8): 1749-57. https://doi.org/10.1016/j.injury.2017.05.037.
12. Smith ST, Cramer KE, Karges DE, Watson JT, Moed BR. Early complications in the operative treatment of patella fractures. J Orthop Trauma. 1997;11(3): 183-7. https://doi.org/10.1097/00005131-199704000-00008.

13. Miller MA, Liu W, Zurakowski D, Smith RM, Harris MB, Vrahas MS. Factors predicting failure of patella fixation. J Trauma Acute Care Surg. 2012;72(4): 1051-5. https://doi.org/10.1097/TA.0b013e3182405296.

14. Kapanen A, Ryhanen J, Danilov A, Tuukkanen J. Effect of nickel-titanium shape memory metal alloy on bone formation. Biomaterials. 2001;22(18): 2475-80. https://doi.org/10.1016/s0142-9612(00)00435-x.

15. Zhang $Y$, Zhao X, Tang Y, Zhang C, Xu S, Xie Y. Application of Ni-Ti alloy connector for the treatment of comminuted coronal plane supracondylar-condylar femoral fractures: a retrospective review of 21 patients. BMC Musculoskelet Disord. 2013;14:355. https://doi.org/10.1186/ 1471-2474-14-355

16. Tian Y, Zhou F, Ji H, Zhang Z, Guo Y. Cannulated screw and cable are superior to modified tension band in the treatment of transverse patella fractures. Clin Orthop Relat Res. 2011;469(12):3429-35. https://doi.org/10. 1007/s11999-011-1913-z

17. Wurm S, Buhren $V$, Augat P. Treating patella fractures with a locking patella plate - first clinical results. Injury. 2018;49(Suppl 1):S51-5. https://doi.org/10. 1016/S0020-1383(18)30304-8

18. Thelen S, Schneppendahl J, Jopen E, Eichler C, Koebke J, Schonau E, Hakimi M, Windolf J, Wild M. Biomechanical cadaver testing of a fixedangle plate in comparison to tension wiring and screw fixation in transverse patella fractures. Injury. 2012;43(8):1290-5. https://doi.org/10. 1016/j.injury.2012.04.020

19. Matejcic A, Smiljanic B, Bekavac-Beslin M, Ledinsky M, Puljiz Z. The basket plate in the osteosynthesis of comminuted fractures of distal pole of the patella. Injury. 2006;37(6):525-30. https://doi.org/10.1016/j.injury.2004.09.020.

20. Taylor BC, Mehta S, Castaneda J, French BG, Blanchard C. Plating of patella fractures: techniques and outcomes. J Orthop Trauma. 2014;28(9):e231-5. https://doi.org/10.1097/BOT.0000000000000039.

21. Zhang $Y$, Wang $P, X i a ~ Y$, Zhou $P, X i e ~ Y, X u ~ S$, Zhang C. Application of a shape-memory alloy concentrator in displaced Patella fractures: technique and long-term results. J Knee Surg. 2017;30(2):166-73. https://doi.org/10. 1055/s-0036-1584187.

\section{Publisher's Note}

Springer Nature remains neutral with regard to jurisdictional claims in published maps and institutional affiliations.

Ready to submit your research? Choose BMC and benefit from

- fast, convenient online submission

- thorough peer review by experienced researchers in your field

- rapid publication on acceptance

- support for research data, including large and complex data types

- gold Open Access which fosters wider collaboration and increased citations

- maximum visibility for your research: over $100 \mathrm{M}$ website views per year

At BMC, research is always in progress.

Learn more biomedcentral.com/submission 